JMI Vol. 41 No. 2, Desember 2019

METAL INDONESIA

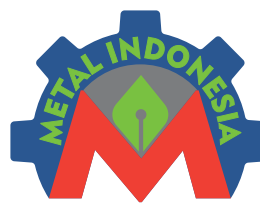

Journal Homepage:

http://www.jurnalmetal.or.id/index.php/jmi

p-issn: 0126-3463

e-issn: 2548-673X

\title{
PENGARUH DOPAN Ni TERHADAP KARAKTERISTIK LISTRIK DAN \\ MAGNETIK PADA ZnO YANG DISINTESIS DENGAN METODE SOLID STATE REACTION
}

\section{THE EFFECT OF DOPAN NI ON ELECTRICAL AND MAGNETIC CHARACTERISTICS IN ZnO SYNTHESIZED WITH SOLID STATE REACTION METHOD}

\author{
Golfrid Gultom ${ }^{1}$, Enda Rasilta Tarigan ${ }^{2}$, Evi Christiani Sitepu ${ }^{3}$ \\ 1,2,3 Jurusan Teknik Mekanika, Politeknik Teknologi Kimia Industri Medan \\ Jalan Medan Tenggara VII Telp. 061.7862439 Medan 20228 \\ Email: ${ }^{1}$ golfridg@ptki.ac.id
}

\begin{abstract}
Abstrak
$\mathrm{ZnO}$ yang memiliki stabilitas kimia serta energi thermal yang tinggi merupakan material non magnetik dan ion Ni yang merupakan salah satu golongan transisi metal yang memiliki sifat magnetik. Kombinasi antara ion $\mathrm{Zn}^{2+}$ dan ion $\mathrm{Ni}^{2+}$ akan menghasilkan material ferromagnetik serta mengakibatkan munculnya perubahan karakteristik listrik dan magnetik. $\mathrm{Zn}_{1-\mathrm{x}} \mathrm{Ni}_{\mathrm{x}} \mathrm{O}(\mathrm{x}=0,0.01,0.03$ dan 0.05) telah disintesis dengan menggunakan teknik Solid-state reaction. Serbuk $\mathrm{ZnO}$ dan $\mathrm{NiO}$ dimixer dan di miling dengan menggunakan high speed shaker mill. Pengaruh dari dopan Ni terhadap sifat listrik dan magnetik telah diinvestigasi dengan menggunakan I-V dan C-V serta VSM. Pengukuran resistivitas, konduktivitas dan konstanta dielektrik dengan menggunakan I-V dan $\mathrm{C}-\mathrm{V}$ meter, diperoleh resistivitas sampel $\mathrm{Zn}_{1-\mathrm{x}} \mathrm{Ni}_{\mathrm{x}} \mathrm{O}(\mathrm{x}=0,0.01,0.03$ dan 0.05$)$ sebesar $\left(3.44\right.$ x $10^{5} \mathrm{ohm} . \mathrm{m}, 3.54$ x $10^{5} \mathrm{ohm} . \mathrm{m}, 3.91 \times 10^{5}$ ohm.m dan $\left.4.80 \times 10^{5} \mathrm{ohm} . \mathrm{m}\right)$. Resistansi yang naik mengindikasikan bahwa perbedaan antara jari-jari ion $\mathrm{Zn}^{2+}$ dan ion $\mathrm{Ni}^{2+}$ menyebabkan internal stress pada sistem kisi $\mathrm{ZnO}$ yang sehingga mengakibatkan cacat pada batas butir (grain boundaries). Konstanta dielektrik sampel $\mathrm{Zn}_{1-\mathrm{x}} \mathrm{Ni}_{\mathrm{x}} \mathrm{O}(\mathrm{x}=0,0.01,0.03$ dan $0.05)$ sebesar $(13,28.36,34.81$ dan 47.55). Konstanta dielektrik yang meningkat diakibatkan karena dengan meningkatnya komposisi dopan, yang diindikasikan $\mathrm{Ni}^{2+}$ dapat menempati posisi pada pusat $\mathrm{Zn}^{2+}$, yang mengarah ke daerah dipol listrik permanen yang menunjukkan perilaku dielektrik. Hasil karakterisasi VSM untuk melihat sifat magnet sampel $\mathrm{Zn}_{1-\mathrm{x}} \mathrm{Ni}_{\mathrm{x}} \mathrm{O}$ menunjukkan sifat ferromagnetik pada seluruh sampel.
\end{abstract}

Kata kunci: ZnO, Solid State Reaction, Dopan Ni, Karakteristik Magnetik, Karakteristik Listrik

\begin{abstract}
$\mathrm{ZnO}$ with high chemical stability and thermal energy is a non magnetic material and Ni ion which is one of the metal transition groups that has magnetic properties. The combination of $\mathrm{Zn}^{2+}$ ions and $\mathrm{Ni}^{2+}$ ions will produce ferromagnetic material and affected material electrical and magnetic characteristics. $\mathrm{Zn}_{1-x} \mathrm{Ni} \mathrm{i}_{x} \mathrm{O}(x=0,0.01,0.03$ and 0.05) has been synthesized using the Solid-state reaction technique. $\mathrm{ZnO}$ and $\mathrm{NiO}$ powders were mixed and miled using high speed shaker mill. The effect of $\mathrm{Ni}$ dopants on electrical and magnetic properties was investigated using I-V and $C$-V and VSM. $Z n_{I-x} N i_{x} O$ $(x=0,0.01,0.03$ and 0.05$)$ resistivity characteristic was $\left(3.44 \times 10^{5}\right.$ ohm.m, $3.54 \times 10^{5}$ ohm.m, $3.91 x$ $10^{5} \mathrm{ohm} . \mathrm{m}$ dan $\left.4.80 \times 10^{5} \mathrm{ohm} . \mathrm{m}\right)$. The increasing of resistance properties indicated by the difference of ion $\mathrm{Zn}^{2+}$ and ion $\mathrm{Ni}^{2+}$ radius. The ions radius difference causes internal stress of $\mathrm{ZnO}$ lattice system which causes grain boundaries. $\mathrm{Zn}_{1-x} \mathrm{Ni} \mathrm{i}_{x} \mathrm{O}(x=0,0.01,0.03$ and 0.05$)$ electric constant properties was
\end{abstract}


$(13,28.36,34.81$ dan 47.55). The increasing of dielectric constant is due to the increasing composition of the dopant, which indicates that $\mathrm{Ni}^{2+}$ can occupy the center of $\mathrm{Zn}^{2+}$, which leads to a permanent electric dipole region that shows dielectric behavior. VSM characterization results to see the magnetic properties of $\mathrm{Zn}_{1-x} \mathrm{Ni}_{x} \mathrm{O}$ samples showed ferromagnetic properties in all samples.

Keywords: ZnO, Solid State Reaction, Ni Dopant, Magnetic properties, Electric properties

\section{PENDAHULUAN}

Perubahan sifat magnetik dalam bahan semikonduktor dilakukan dengan doping elemen-elemen transition-metal (TM), misalnya $\mathrm{Sc}, \mathrm{Ti}, \mathrm{V}, \mathrm{Cr}, \mathrm{Mn}, \mathrm{Fe}, \mathrm{Co}, \mathrm{Ni}$, dan $\mathrm{Cu}$ (Vijayaprasth et al ., 2015). Kontrol dan tuning sifat magnet di dalam dilute magnetic semiconductor (DMS) seperti $\mathrm{ZnO}, \mathrm{TiO}_{2}$, dan $\mathrm{SnO}_{2}$ telah banyak dipelajari pada beberapa dekade terakhir ini. $\mathrm{ZnO}$ memiliki kelebihan dibanding dengan material yang lain, diantaranya: murah, tidak beracun dan ramah lingkungan (Das et al ., 2015). ZnO merupakan material semikonduktor yang memiliki stabilitas kimia dan termal yang tinggi, dengan celah pita energi yang besar yaitu $3.37 \mathrm{eV}$ dan energi ikat exciton sebesar $60 \mathrm{MeV}$ (Srinet et al ., 2013). Hal itu menjadikan $\mathrm{ZnO}$ berpotensi dalam banyak aplikasi, seperti sel surya, optoelektronik, magnetic tunnel junctions, potovoltaics, lightemitting diodes, perangkat berbasis spintronik dan sensor (Dogan et.al 2014). Temperatur ruang ferromagnetik (Room-temperature ferromagnetism) dalam sistem $\mathrm{ZnO}$ doping transisi metal khususnya $\mathrm{Ni}$ telah dipelajari secara intensif dalam beberapa tahun ini (Jadhav et al ., 2013).

Untuk memperoleh DMS yang bersifat ferromagnetik dengan momen magnetik yang besar dan temperatur Curie yang tinggi namun dengan energi gap yang lebar. Nikel adalah unsur yang efisien sebagai dopan untuk memperbaiki sifat listrik dan magnet dari semikonduktor $\mathrm{ZnO}$ karena jari-jari ionik $\mathrm{Ni}$ dengan $\mathrm{Zn}$ yang hampir sama, dan keadaan elektron yang divalent. Membuat Ni menjadi dopan yang baik karena dapat dengan mudah masuk ke dalam kisi kristal $\mathrm{ZnO}$ atau mensubsitusi posisi $\mathrm{Zn}$ didalam kristal posisi $\mathrm{ZnO}$ (Pala et al ., 2015). Namun hal-hal yang berkontribusi terhadap kehadiran sifat Ferromagnetik dari semikonduktor $\mathrm{ZnO}$ yang didoping dengan logam transisi masih menjadi kontroversial dan perdebatan dalam penelitian (Pala et al ., 2015, Coleman et al ., 2006).

$\mathrm{ZnO}$ doping $\mathrm{Ni}$ telah dipelajari dengan barbagai metode sintesis yang berbeda, seperti solid state reaction (Srinet et al ., 2013), sol-gel
(Coleman et al ., 2006), kopresipitasi (Dogan et al ., 2014, Jadhav et al ., 2013, Shinde et al ., 2014), sputtering ( Liu et al ., 2009, AbdelWahab et al ., 2016) dan hidrotermal (Zhong et al ., 2016). Metode solid state reaction dengan menggunakan alat milling merupakan metode yang paling murah dan sederhana dalam skala laboratorium. Pada penelitian ini dilakukan sintesis $\mathrm{ZnO}$ doping $\mathrm{Ni}$ dengan metode solid state reaction menggunakan high speed shaker mill.

\section{METODOLOGI}

Sintesis $\mathrm{Zn}_{1-\mathrm{x}} \mathrm{Ni}_{\mathrm{x}} \mathrm{O}$ dilakukan dengan metode Solid state reaction dengan material awal $\mathrm{ZnO}$ and $\mathrm{NiO}$. Serbuk $\mathrm{ZnO}$ dan $\mathrm{NiO}$ dicampur dan dihaluskan (milling) di dalam cylindrical stainless steels vial dengan menggunakan high speed shaker mill. Steell ball yang digunakan memiliki diameter $(\phi) 4 \mathrm{~mm}$ dan perbandingan berat antara serbuk dengan bola adalah 1:10. Proses tersebut dilakukan dalam kondisi basah dengan menambahkan toluene sebagai solventnya selama 3 jam. Serbuk hasil milling (milled powder) dikeringkan di dalam oven selama 3 jam dengan suhu $100^{\circ} \mathrm{C}$ dan selanjutnya dibuat bentuk pellet. Proses press dilakukan dengan menggunakan automatic axial hydrolic press $1500 \mathrm{kgf} / \mathrm{cm}^{2}$. Sampel pellet memiliki diameter $15 \mathrm{~mm}$ dan ketebalan $2 \mathrm{~mm}$. pada tahap akhir, sampel disintering pada temperatur $900{ }^{\circ} \mathrm{C}$ dengan waktu penahanan 2 jam di atmosfir udara. Struktur kristal dari pellet $\mathrm{Zn}_{1-\mathrm{x}} \mathrm{Ni}_{\mathrm{x}} \mathrm{O}$ di investigasi dengan menggunakan $\mathrm{X}$-ray diffraction (XRD) $(40 \mathrm{KV}, 30 \mathrm{~mA})$ Smartlab -Rigaku. Sifat listrik dan sifat magnet dari sampel dianalisis dengan menggunakan I-V meter FLUKE 8842A Multimeter, C-V meter Keithley 590 C-V Analyzer meter dan Vibrating Sample Magnetometer Oxford types VSM 1.2 H.

\section{HASIL DAN PEMBAHASAN}

Hasil karakterisasi XRD dari semua puncak yang berurutan dari sudut $2 \theta$ dari $20^{\circ}-80^{\circ}$ yang secara berurutan berhubungan dengan bidang (100) (002) (101) (102) (110) (103) (200) (112) (201) (004) dan (202) struktur wurtzite 
ZnO. Gambar 1(a) memperlihatkan bahwa sampel yang telah disintesis dari konsentrasi dopan $1 \%$ atom hingga $5 \%$ atom $\mathrm{Ni}$ memiliki sruktur utama $\mathrm{ZnO}$ hexagonal wurtzite. Hal ini dapat dilihat dengan jelas pada puncak difraksi dari ketiga sampel yaitu pada sudut $31,77^{\circ}$ yang berhubungan dengan bidang $\left(\begin{array}{lll}1 & 0 & 0\end{array}\right)$ pada struktur wurtzite $\mathrm{ZnO}$.
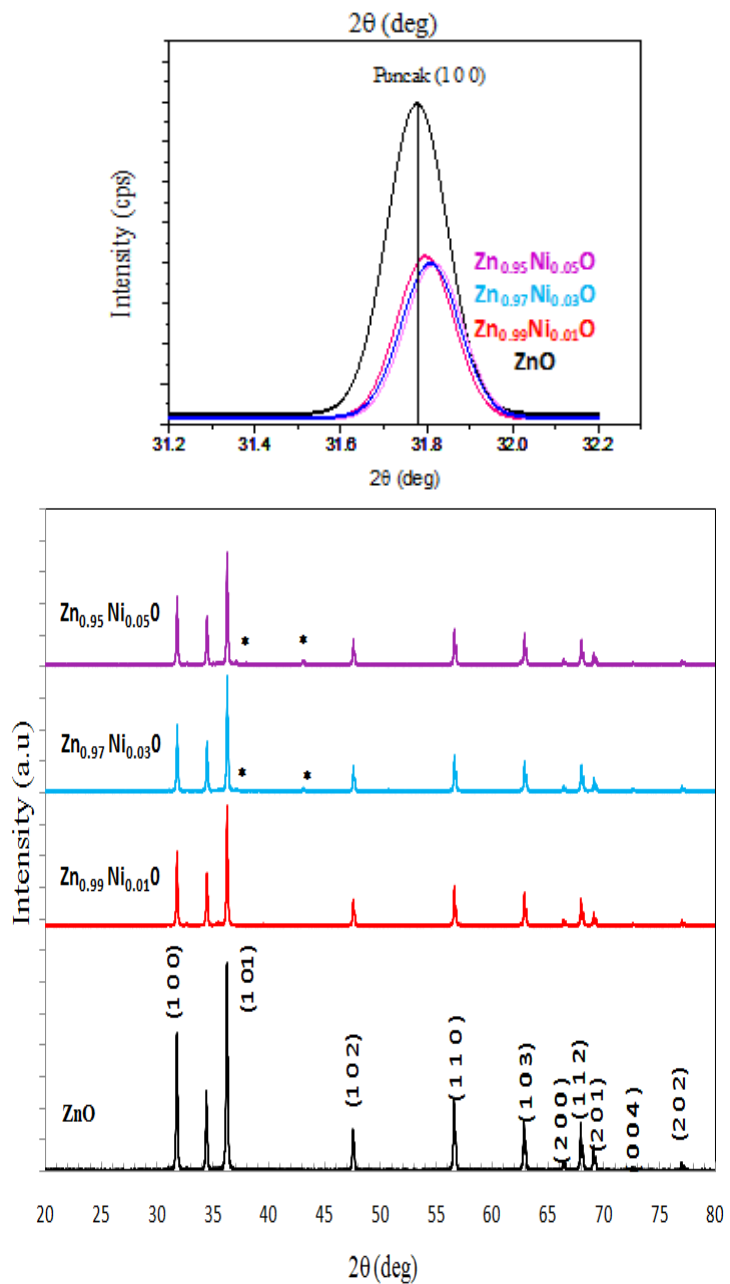

Gambar 1. Pola difraksi sinar $\mathrm{X}$ dari sampel $\mathrm{Zn}_{1}$. ${ }_{x} \mathrm{Ni}_{\mathrm{x}} \mathrm{O} \quad(\mathrm{x}=0,1,3,5 \%$ atom $)$, (inzet) Pengamatan detail $\mathrm{ZnO}$ pada bidang (001)

Puncak tambahan yang berhubungan dengan fasa impuritas terjadi pada sampel dengan konsentrasi $3 \%$ dan $5 \%$ atom $\mathrm{Ni}$, kehadiran puncak tambahan pada sampel $\mathrm{ZnO}$ didop Ni menunjukkan fasa Nickel Zinc Oxide yang dipengaruhi oleh kenaikan konsentrasi dopan pada sampel tersebut (puncak tambahan yang terbentuk dapat dilihat jelas pada Gambar 1. Kehadiran fasa impuritas pada pola difraksi berkaitan dengan solubilitas atom $\mathrm{Ni}$ dalam $\mathrm{ZnO}$, dimana kelarutan $\mathrm{Ni}$ dalam $\mathrm{ZnO}$ hanya sekitar 5\% dengan teknik ball milling. Puncak tambahan juga dapat diakibatkan oleh jari-jari ion pada matriks dan dopan sangat berbeda, yang dapat menyebabkan munculnya dislokasi. Indikasi lainnya, terbentuknya fase impuritas karena metode dalam fabrikasi sampel dan bahan baku yang digunakan dalam penelitian diyakini berpengaruh pada munculnya fase impuritas.

Gambar 1 menunjukkan pergeseran puncak-puncak difraksi pada bidang $\left(\begin{array}{lll}1 & 0 & 0\end{array}\right)$ ke arah sudut 2 tetha yang lebih besar, sedangkan intensitas difraksi menurun dari masing-masing sampel $\mathrm{ZnO}$ didop Ni. Dimana intensitas dan FWHM, dari masing-masing sampel digunakan untuk menentukan ukuran rata-rata kristalit (D).

Penentuan dilakukan dengan DebyeScherrer formula, yaitu $D=0.9 \lambda /(\beta \operatorname{Cos} \theta)$ dimana $\lambda$ merepresentasikan panjang gelombang radiasi sinar-X, $\beta$ adalah nilai FWHM (Full Width at Half Maximum) dan $\theta$ adalah sudut difraksi, dan dari kurva yang ditampilkan pada gambar 1 diketahui pelebaran pada FWHM seiring dengan penambahan konsentrasi atom $\mathrm{Ni}$ yang menyebabkan ukuran rata-rata kristalit meningkat. Nilai FWHM pada posisi puncak (1 0 0) ditunjukkan dalam Tabel 1.

Pergeseran puncak ke arah sudut yang lebih besar juga membuktikan terjadinya perubahan parameter kisi dari struktur kristal $\mathrm{ZnO}$ didop Ni (tabel 1). Namun nilai parameter kisi dalam penelitian ini lebih kecil jika dibandingkan dari teori (ICCD No. 00-005-0664 $\mathrm{a}=3,249 \AA$, dan $\mathrm{c}=5,205 \AA$ ), parameter kisi a, c dan mengalami penurunan setelah dengan bertambahnya konsentrasi dopan Ni. Hal ini mengindikasikan bahwa atom $\mathrm{Ni}^{2+}$ berhasil tergabung dalam kisi $\mathrm{ZnO}$ pada kisi $\mathrm{Zn}^{2+}$, dan ini terjadi karena jari-jari ionik dari $\mathrm{Ni}^{2+} 0,55 \AA$ sementara jari-jari $\mathrm{Zn}^{2+} 0,60 \AA$. 
Tabel 1. Parameter kisi sampel $\mathrm{Zn}_{1-\mathrm{x}} \mathrm{Ni}_{\mathrm{x}} \mathrm{O}(\mathrm{x}=0,1,3,5 \%$ atom $)$

\begin{tabular}{cccccccc}
$\begin{array}{c}\text { \% atom } \\
\mathrm{Ni}\end{array}$ & $\mathrm{a}(\AA)$ & $\mathrm{c}(\AA)$ & $\mathrm{c} / \mathrm{a}$ & $\mathrm{d}(\AA)$ & $\mathrm{FWHM}\left({ }^{\circ}\right)$ & $\begin{array}{c}\text { Intensitas } \\
(\mathrm{cps})\end{array}$ & $\mathrm{D}(\AA)$ \\
\hline 0 & 3.249 & 5.205 & 1.602 & 2.814 & 0.165 & 1543.9 & 50.6 \\
1 & 3.246 & 5.199 & 1.601 & 2.812 & 0.157 & 802.8 & 52.6 \\
3 & 3.248 & 5.202 & 1.601 & 2.810 & 0.158 & 765.8 & 51.9 \\
5 & 3.245 & 5.198 & 1.601 & 2.811 & 0.159 & 763.9 & 51.8 \\
\hline
\end{tabular}

Pengujian sifat listrik $\mathrm{ZnO}$ yang di doping dengan Ni menggunan I-V dan $\mathrm{C}-\mathrm{V}$ meter

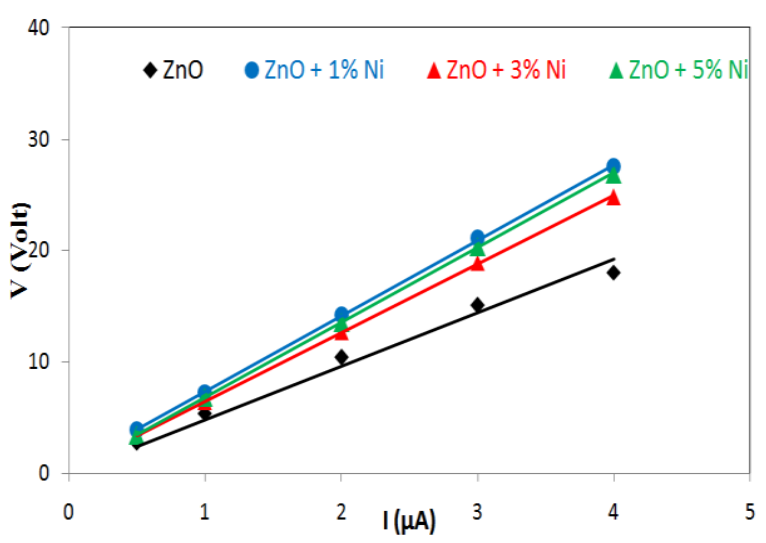

Gambar 2. Grafik hasil pengukuran I-V sampel $\mathrm{Zn}_{1-\mathrm{x}} \mathrm{Ni}_{\mathrm{x}} \mathrm{O}(\mathrm{x}=0,1,3,5 \%$ atom $)$

Karakterisasi dari analisis I-V meter adalah untuk menganalisis resistivitas dan konduktivitas, sedangkan karakterisasi C-V meter adalah untuk menganalisis konstanta dielektrik dari sampel uji dan untuk mengukur nilai kapasitansi dari sampel $\mathrm{ZnO}$ murni dan $\mathrm{ZnO}$ didoping Ni. Pengukuran dilakukan pada suhu kamar dalam lingkungan atmosfir dengan frekuensi alat diatur pada $1 \mathrm{MHz}$. Diperoleh rentang nilai bahan sampel $\mathrm{ZnO}$ murni mempunyai nilai resistivitas $\left(\rho=3,44 \times 10^{5}\right.$ ohm.m) sedangkan konduktivitas $\left(\sigma=2,90 \times 10^{-}\right.$ ${ }^{6} \mathrm{~S} / \mathrm{m}$ ), yang menujukkan dalam semikonduktor. Penambahan dopan Ni diindikasikan dapat meyebabkan cacat kristal (Dianguang et al ., 2016). Pergerakan muatan terhambat oleh kehadiran cacat pada batas butir, yang menyebabkan kenaikan nilai resistivitas. Selain itu, kekosongan oksigen juga diyakini berkontribusi pada nilai konduktivitas listrik (Liu et al ., 2009). Meningkatnya konsentrasi Ni, nilai resistivitas semakin menurun yang menunjukkan ukuran butir yang semakin menurun yang diperkirakan membuat nilai resistivitas juga menurun dapat di lihat pada Tabel 2. Diperoleh bahwa sampel $\mathrm{ZnO}$ murni mempunyai konstanta dielektrik sebesar 12,5. Hasil ini dapat dibandingkan dengan laporan penelitian yang dilakukan oleh (Barker et al., 1997) dimana dilaporkan bahwa sampel film tipis $\mathrm{ZnO}$ yang dipreparasi dengan r.f. magnetron sputtering mempunyai konstanta dielektrik sebesar 13 dan (Das et al., 2015) melaporkan konstanta dielektrik sebesar 11,25 dari sampel $\mathrm{ZnO}$ murni yang disintesis dengan coprecipitation method dan disintering pada suhu $1300{ }^{\circ} \mathrm{C}$.

Dari Tabel 2 diperoleh bahwa terjadinya kenaikan konstanta dielektrik dengan meningkatnya konsentrasi dopan $\mathrm{Ni}$, perubahan ini dapat dijelaskan atas dasar perbedaan jari-jari ion antara $\mathrm{Zn}^{2+}$ dan ion dopan $\mathrm{Ni}^{2+}$. Karena $\mathrm{Ni}^{2+}$ dapat menempati posisi dipusat $\mathrm{Zn}^{2+}$, yang mengarah ke daerah dipol listrik permanen yang menunjukkan perilaku dielektrik. Aspek lain untuk perilaku dielektrik adalah karena vacansi oksigen (Srinet et al ., 2013; Ghoshet ., al 2008). Kekosongan oksigen menghasilkan batas butir yang tidak seragam yang mengakibatkan elektron mengalami polarisasi, terjadinya mekanisme polarisasi dalam bidang dielektrik akan berdampak bertambah besarnya muatan listrik yang tersimpan.

Tabel 2. Resistivitas,konduktivitas, kapasitansi dan kontanta dielektrik dari sampel $\mathrm{Zn}_{1-\mathrm{x}} \mathrm{Ni}_{\mathrm{x}} \mathrm{O}(\mathrm{x}=0,1,3,5 \%$ atom $)$

\begin{tabular}{ccccc}
\hline $\begin{array}{c}\text { Konsentrasi } \\
\mathbf{N i}(\boldsymbol{\%})\end{array}$ & $\begin{array}{c}\boldsymbol{\rho} \\
(\mathbf{o h m . c m})\end{array}$ & $\begin{array}{c}\boldsymbol{\sigma} \\
(\mathbf{S} / \mathbf{c m})\end{array}$ & $\begin{array}{c}\mathbf{C} \\
(\mathbf{p F})\end{array}$ & $\boldsymbol{\varepsilon}_{\mathbf{r}}$ \\
\hline 1 & $3.54 \times 10^{7}$ & $2.80 \times 10^{-\varepsilon}$ & 19,8 & 28,3 \\
& & & 6 & 6 \\
3 & $3.91 \times 10^{7}$ & $2.56 \times 10^{-\varepsilon}$ & 31,7 & 34,8 \\
& & & 1 & 1 \\
5 & $4.80 \times 10^{7}$ & $2.08 \times 10^{-\varepsilon}$ & 25,2 & 47,5 \\
& & & 9 & 5 \\
\end{tabular}




\section{Analisis Hasil Karakterisasi Sifat Magnet}

Dari uji karakteristik sifat magnet menggunakan VSM diperoleh kurva histerisis yang diperoleh serta nilai koersivitasnya dan nilai remanensi. Dengan mengetahui koersivitasnya maka akan diketahui tingkat keberhasilan penambahan bahan dopan Ni. Koersivitas adalah ketahanan bahan magnetik untuk mengubah magnetisasi bahan tersebut, atau besarnya kuat medan magnetik yang diaplikasikan untuk mendemagnetisasi (mengurangi magnetisasi bahan menjadi nol). Peningkatan konsentrasi dopan menyebabkan peningkatan nilai koersivitas, dimana semakin besar gaya koersivitasnya maka semakin tinggi sifat magnetnya sedangkan saturasinya (Ms) meningkat dengan penambahan konsentrasi bahan dopan Ni. Nilai saturasinya (Ms) meningkat (Tabel 3) dengan kenaikan konsentrasi dopan Ni telah dilaporkan (Liu et al ., 2014). Sifat ferromagnetik dalam sampel berasal dari interaksi double exchange antara hole yang bebas dan elektron dari pita valensi atau interaksi pertukaran antara host kisi $\mathrm{ZnO}$ dan ion magnetik (Vijayaprasath et al ., 2015; Jeevan, et al ., 2013).

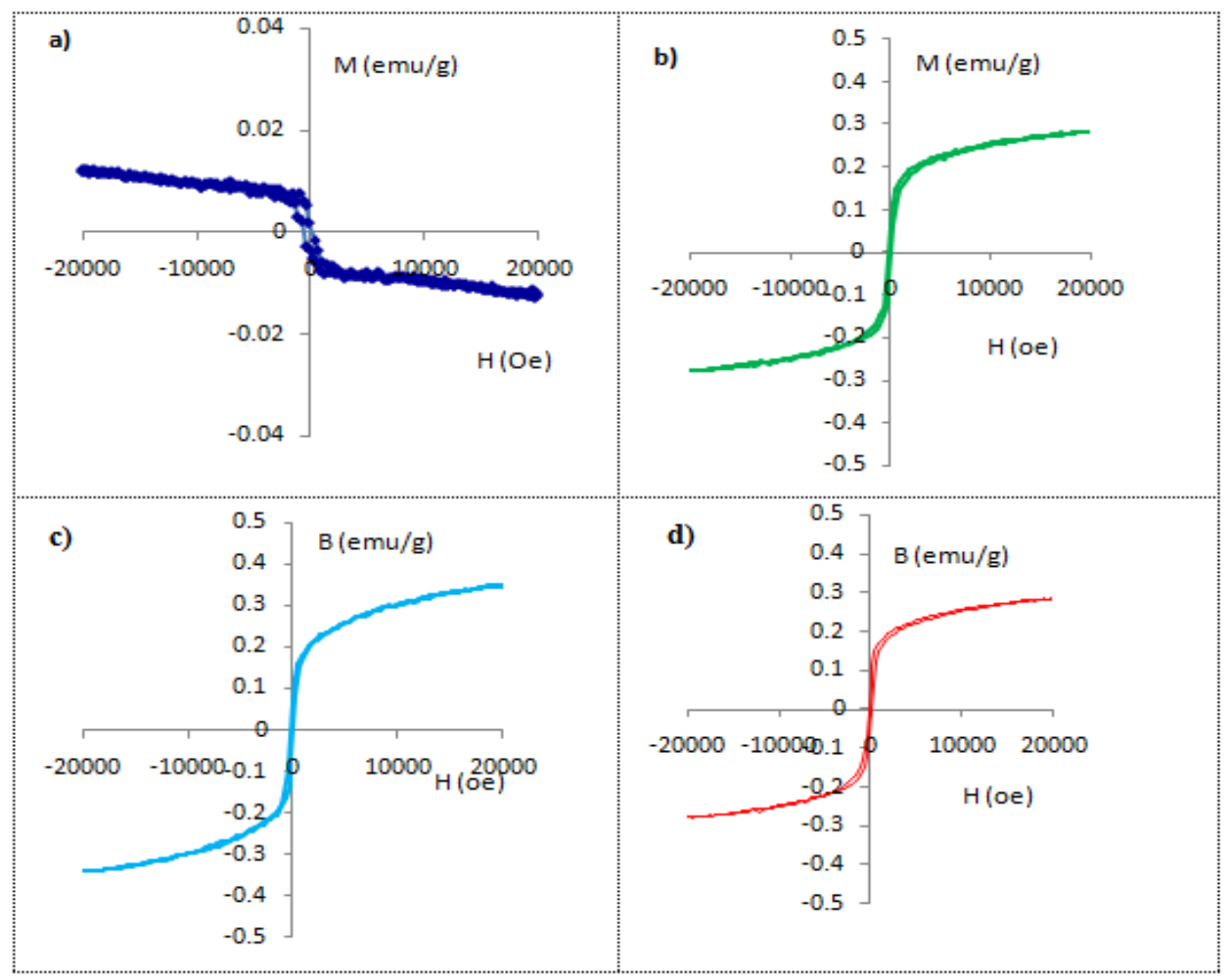

Gambar 3. (a) Kurva Histerisis pada sampel $\mathrm{ZnO}$ murni, (b) Kurva Histerisis pada sampel $\mathrm{Zn}_{1-\mathrm{x}} \mathrm{N}_{\mathrm{x}} \mathrm{O}(1 \%$ atom $\mathrm{Ni}$ ), Kurva Histerisis pada sampel $\mathrm{Zn}_{1-\mathrm{x}} \mathrm{N}_{\mathrm{x}} \mathrm{O}(3 \%$ atom $\mathrm{Ni})$, Kurva Histerisis pada sampel $\mathrm{Zn}_{1-\mathrm{x}} \mathrm{N}_{\mathrm{x}} \mathrm{O}(5 \%$ atom $\mathrm{Ni})$.

Tabel 3. Hasil perhitungan Koersivitas dan remanensi sampel sampel $\mathrm{Zn}_{1-\mathrm{x}} \mathrm{Ni}_{\mathrm{x}} \mathrm{O}(\mathrm{x}=0,1,3,5 \%$ atom $)$

\begin{tabular}{cccc}
\hline \multirow{2}{*}{$\begin{array}{c}\text { Sampel } \\
\mathbf{Z n}_{\mathbf{1 - x}} \mathbf{N i}_{\mathbf{x}} \mathbf{O}\end{array}$} & $\mathbf{3}$ Sifat Magnet \\
\cline { 2 - 4 } & $\mathbf{M r}(\mathbf{e m u} / \mathbf{g})$ & $\mathbf{H c}(\mathbf{O e})$ & $\mathbf{M s}(\mathbf{e m u} / \mathbf{g})$ \\
\hline 1 & 0,041 & 112,50 & 0,184 \\
3 & 0,048 & 109,04 & 0,270 \\
5 & 0,038 & 147,78 & 0,281 \\
\hline
\end{tabular}

Sifat ferromagnetik yang terbentuk karena adanya fasa impuritas disebut ekstrinsik ferromagnetik, sedangkan sifat ferromagnetik $\mathrm{ZnO}$ didop $\mathrm{Ni}$ tanpa adanya fasa impuritas 
disebut ferromagnetik instrinsik dan ini masih menjadi kontroversi (Sinde et al ., 2014;Zhong et al ., 2016). $\mathrm{ZnO}$ didop $\mathrm{Ni}$ bersifat ferromagnetik, ini sudah dilaporkan oleh (Pala, et. at., 2015; Jeevan et al ., 2015; Shindeet al ., 2014; Liu et al., 2014; Gunjan et. al ., 2013) sifat ferromagnetik terbentuk karena sebagian ion $\mathrm{Ni}^{2+}$ mensubstitusi ion $\mathrm{Zn}^{2+}$ dalam kisi $\mathrm{ZnO}$ adanya interaksi pertukaran antara elektron daerah spin-terpolarisasi dari $\mathrm{Ni}^{2+}$ dan elektron konduksi atau pembawa muatan bebas yang disebabkan interaksi ferromagnetik.

\section{KESIMPULAN}

$\mathrm{Zn}_{1-\mathrm{x}} \mathrm{Ni}_{\mathrm{x}} \mathrm{O}$ telah disintesis dengan metode solid state reaction. Sifat listrik dan magnetik menunjukkan perubahan terhadap penambahan konsentrasi dopan Ni. Sample $\mathrm{Zn}_{1-}$ ${ }_{x} \mathrm{Ni}_{\mathrm{x}} \mathrm{O}$ memiliki nilai resistivitas yang semakin menurun sedangkan konduktivitas dan kapasitansi yang semakin meningkat dengan kenaikan bahan doping Ni. Pengukuran VSM menunjukkan semua sampel $\mathrm{Zn}_{1-\mathrm{x}} \mathrm{Ni}_{\mathrm{x}} \mathrm{O}$ bersifat ferromagnetik. Dan diperoleh nilai magnetik saturasi meningkat dengan semakin meningkatnya konsentrasi dopan $\mathrm{Ni}$.

\section{DAFTAR PUSTAKA}

A. Barker, S. Crowther, D. Rees, Room temperature rf magnetron sputtered $\mathrm{ZnO}$ for electromechanical devices, Sensors and Actuators A. 58 (1997) 229-235.

Bappaditya Pala, D. Sarkara, P.K. Girib, 2015 Science 356, 804-811.

Dianguang Liu, Yan Gao, Jinling Liu, Yiguang Wang, Linan An, 2016, j.ceramics internasional.08.048.

G. Vijayaprasath, R. Murugana, S. Asaithambia, P. Sakthivela, T. Mahaling4, Y. Hayakawa and G.Ravi, 2015, Ceramics International.

Gunjan Srinet, Dielectric studies of $\mathrm{Ni}$ and $\mathrm{Ba}$ doped Zno Samples;Ceramic International, vol. 40, pp. 4025, 2014. AIP Conference Proceedings, vol. 1536, pp. 247, 2013).

Gunjan Srinet, Ravindra Kumar, and Vivek Sajal, 2013 Journal Of Applied physics 114, 033912.

J.Das, D.K. Mishra, V.V. Srinivasu, D.R. Sahu, and B.K. Roul, 2015 Journal of Magnetism and Magnetic Materials 382 111-116.
Jeevan Jadhav, Mahesh Patange, and Somnath Biswas, 2013, Carbon - Science and Technology ISSN 0974 - 0546

Jeevan Jadhav and Somnath Biswas, Shapecontrolled magnetic nanoplatelets of $\mathrm{Ni}$ doped $\mathrm{ZnO}$ synthesized via a chemical precursor* Department of Physics, The LNM Institute of Information Technology, Jaipur - 302031, India. 2015

K.P. Shinde, R.C.Pawar, B.B.Sinha, H.S.Kima, S.S.Oha, K.C.Chung, 2014,Ceramics International

M. Kakazey a,n, M.Vlasov, Y.Vorobiev, I.Leon, M.CabeceraGonzalez, Edgar Arturo Chávez Urbiola, 2014, Physica B.

M.Sh. Abdel-wahab, Asim Jilani, I.S. Yahia, Attieh A. Al-Ghamdi, 2016, Superlattices and Microstructures.

Min Zhong, Ying Li, Muhammad Tariq, Yemin $\mathrm{Hu}$, Wenxian Li, Mingyuan Zhu, Hongmin Jin, Yibing Li, 2016, Journal of Alloys and Compound.

N. Doğan,A.Bingölbali, L.Arda, 2014 Journal of Magnetism and Magnetic Materials Science.

V. A. Coleman and C. Jagadish, 2006, Department of Electronic Materials Engineering,Research School of Physical Sciences andEngineering, The Australian National University, Canberra, ACT 0200, Australia.

X J Liu, X Y Zhu, C Song, F Zeng and F Pan, 2009 J. Phys. D: Appl. Phys. 4203500. 